\title{
Obituary
}

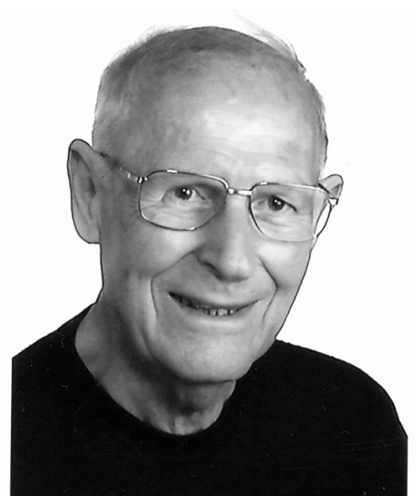

\section{Professor Jørgen Fris Jensen}

Jørgen Fris Jensen died on $13^{\text {th }}$ March 2010 at the age of 82 .

Fris Jensen was born on 26 September 1927 in Aarhus, Denmark. After a practical education in farming and studying at the Royal Veterinary and Agricultural University in Copenhagen he became Master of Animal Science in 1954 and obtained his $\mathrm{PhD}$ in 1959. He then became a researcher, working with poultry and rabbits at the National Institute of Animal Science.

In 1972 Fris Jensen was appointed Professor at the Royal Veterinary and Agricultural University, covering the disciplines of poultry breeding and nutrition. In this role he was responsible for supervising several Ph.D. students working with poultry. Prof. Jensen always enjoyed the scientific education of students and demonstrated a thorough knowledge of the field in many aspects. At the same time he became Head of the Department in which he had previously worked. Following structural changes in the National Institute of Animal Science, Fris Jensen retired from this in 1993, but continued as Professor at the Royal Veterinary and Agricultural University in Copenhagen.

Fris Jensen has been involved in the work of a number of councils and committees. Since 1976 he has been Chairman of the National Council for Feedstuffs and, since 1989, of the National Committee on Feed Additives. For a great many years he held a place on the EEC Standing Committee on Agricultural Research and, since 1991, was a member of the Danish Animal Ethics Council.

Poultry production always interested Fris Jensen, both from a practical point of view and as a subject for research, and this made him a valuable link between poultry science and commercial production. These interests brought him into the WPSA at an early stage, and, for many years, he was concerned with the possibilities that this organization provided. Within the framework of the European Federation of WPSA Branches he became a main driving force behind the introduction of symposia, and stressed the importance of the various tasks undertaken by the Working Groups. He was a member of the Poultry Meat Quality working group from 1974, and its chairman from 1976 to 1986. During this time he helped establish some important procedures and guidelines for the scientific symposia programmes and these continue to be used by this and other Working Groups. As a Council Member of the European Federation of WPSA Branches and a member of the Executive Committee of the WPSA itself, he was involved in the management of the whole Organization. In 1986 he was elected President of the WPSA European Federation, continuing in this post for two consecutive four-year terms.

Prof. Jensen was a prolific author, publishing many scientific articles on poultry production. His work is characterized by stringent accuracy and great practicality, helping to make it immediately usable by those directly involved in poultry 
production. He was editor of Methods of dissection of broiler carcasses and description of parts published by Working Group 5 and Terms used for parts of poultry in different languages (WPSJ 1993; 39: 64-73). These publications continue to be valuable tools and remain fine examples of the output from an active Working Group.

In 1991, and in recognition of his work in the area of poultry meat quality, Fris Jensen received an Honorary Doctorate from Pannonia Agricultural University in Hungary. He was subsequently honoured by the award of the Order of Knight of The Dannebrog, $1^{\text {st }}$ Degree.

In 1996, Prof. Jensen was incorporated in the WPSA's Hall of Fame and in the following year he retired after 25 active years as a researcher and teacher. After retirement, he continued to participate in the work of the Danish poultry production by taking on various tasks, which was greatly appreciated. He continued to actively participate in the WPSA events long after his retirement. Until the very end he was an active debater, reknown for his pertinent comments in scientific discussions.

Although a very active professional life may have come to an end, Prof. Fris Jensen's comprehensive efforts in different poultry production leaves a strong legacy.

Thorkil Ambrosen and Sanna Steenfeldt 